\title{
Are Design Codes Appropriate in Mining Rock Engineering?
}

\author{
T.R. Stacey University of the Witwatersrand, South Africa
}

\begin{abstract}
In the civil engineering field the use of design codes is common. One of the main purposes of such codes is to ensure that 'standardised' and proven design procedures and designs are carried out, incorporating adequate factors of safety and that the safety of the public is therefore protected. In the mining environment there is usually no access to mining excavations by members of the public and only experienced mining personnel have such access. Visitors to a mine are always accompanied by experienced one of such personnel. In addition, mining excavations often have a much shorter life than civil excavations and economy of operation is essential to optimise the profitability of mining operations. The perception of risk in the two environments is therefore understandably different. Is a process similar to that used in civil engineering, in which codefied designs are used, appropriate in the rock engineering field in mining? This question will be considered in the paper, making use of relevant civil engineering codes and the former guideline document issued by the South African Department of Minerals and Energy for the compilation of a Mandatory Code of Practice to combat rock fall and rockburst accidents in mines. In addition, moral and ethical issues associated with engineering design will be considered in answering the question.
\end{abstract}

\section{Introduction}

In mining there are several areas in which design is guided rigorously. For example, the design of hoist ropes in South Africa is governed by the Regulations of the Minerals Act (2001). These specify required factors of safety for winding ropes under different conditions, and for frequencies of examination of the ropes and recording of details of the ropes. Have these 'mechanical' specifications been introduced because they are easy: materials are well defined, loading conditions are known, routine inspection and testing is not difficult, etc.? In mining, in contrast, conditions are often unknown or uncertain and testing and monitoring are difficult, often because of the dynamic nature of the mining - faces advance every day and often little is known about the rock ahead of the face. Does this mean that design and construction under these conditions must be, or are allowed to be, less rigorous? As an introduction to the consideration of this question, it is perhaps appropriate to summarise some differences between civil and mining engineering situations. Two areas will be covered to provide the context in which discussion will follow. These are:

- The different demands of mining and civil engineering situations.

- The different requirements of design and of prediction of behaviour.

The main purpose in mining is to extract ore and to generate as much value as possible, and the creation of any excavations is simply a means to this end. The geometries of stoping excavations are often dictated by the shape of the orebody. Some of the concepts relevant to mining excavations are:

- Safety must be ensured where there is human access.

- Stability is a concept whose meaning is determined by the mining requirements:

- In caving mining methods, instability is a requirement for successful and safe mining.

- In open stoping methods, stopes must remain substantially stable.

- Service excavations such as shafts, main access and haulage tunnels and chambers (pump, hoist, refrigeration, etc.) must be stable for their required life span.

- Failure may relate more to serviceability than to failure of the rock or support - as long as the excavation remains satisfactorily open and permits safe and efficient operation, it can be said not to have failed. In such cases, the use of rock strength failure criteria for the evaluation of stability may 
be questioned. Excavations should be close to the stability limit, and designs should allow for a substantial risk. In fact, occasional failure of excavations should occur, provided that this is not unexpected. If no excavations fail, then it is probable that they are being too conservatively, hence uneconomically, designed. Mining excavations should ideally start to fail very soon after the mining operation has ceased. These conditions imply that adequate monitoring of excavations is being carried out.

- Facilities and equipment to carry out rehabilitation in the event of any failure are usually readily available and do not require special mobilisation.

- Time has a meaning determined by the mining requirements. The life of the mining operation is determined by the known extent of the orebody and the rate of extraction, both of which can change during the progress of the mining operations. Requirements in mining situations are therefore often dynamic. Excavations will be designed for the appropriate life span. Since mining economics are critical, it is inappropriate to design an excavation to be stable for longer than the required life.

It will be clear from the above that different mining excavations must be designed for different probabilities of failure and that the values of the probabilities of failures will usually be much greater than those for civil engineering excavations.

In contrast with the above, likely requirements for civil engineering excavations are:

- Long-term stability (say 100 years) since there is usually some public access to most excavations.

- Stability and support must be commensurate with the projected life of the excavation. The minimising of support costs is not appropriate, and usually the cost of implementing the right, or even very conservative, support is small in relation to the overall project cost. It is important that the right support (type and quantity) is designed and installed according to the design.

- Cracking of concrete or shotcrete, or a small amount of deformation, may be interpreted as failure. The excavations must be designed with a very low probability of failure (i.e. with a high factor of safety).

- The consequences of failure may be severe. For example, a hydroelectric power station may become inoperable or an underground railway system may be blocked due to an occurrence of instability, leading to large economic losses. The instability may be small but the consequences may be large.

- Facilities and equipment are usually not available on site to carry out rehabilitation in the event of instability. They will have to be mobilised by means of a special contract.

With the different requirements for mining and civil engineering excavations, the attitudes and thinking in the two areas with regard to design and the evaluation or prediction of behaviour, are correspondingly different. Engineers are taught to design any structures they may create. A simplified engineering design process will include:

- A definition of the problem and design objectives.

- The identification of possible mechanisms of behaviour and possible solutions to the problem.

- Definition of suitable design criteria for each solution and decision on the factor of safety, or probability of failure, to be applied.

- Determination of input parameters for the design process (for example, strength, deformability). Such values may have some degree of conservatism built into them.

- The execution of design calculations to produce a design which satisfies the set criteria.

- Implementation, and monitoring to ensure that the structure is behaving according to the design.

Owing to the alternative ideas of different engineers, this process could result in a variety of designs, all of which will be solutions to the problem. All of the solutions will have different overall factors of safety and conservatism built into them. Although the design process may be complicated from a calculation point of view, it is an easy one from a decision point of view. Decisions become easier as the conservatism of the 
design increases. As an example of this, consider an excavation in a reasonably sparsely jointed, stratified rock mass. Design criteria that could be applicable are beam stability, wedge/block stability, rock mass stability and possibly stability against stress induced failure. Conservatively designed support will probably easily satisfy the requirements of all of these behaviours without detailed calculations being necessary.

\section{Design codes and their benefits}

Codes are usually introduced for safety reasons. They may be in the form of design codes or codes of good practice. They may be prescriptive in nature, involving prescription of methods such as design methods, prescriptive of solution, such as rock support and its type, or they may provide recommendations without prescription. An example of a code is a Code of Practice for Lateral Support in Surface Excavations (SAICE, 1989). The first edition of this code was introduced as a result of "problems related to safety of excavations for deep basements." It is very comprehensive and generally non-prescriptive, and includes recommendations for site investigations, for selection of a lateral support system, for considerations of earth pressures, for design of lateral support systems and for design and construction of ground anchors. It also deals with control of groundwater, the works, monitoring and records. With regard to (slope) stability of the faces of the excavation, it states that, "it is generally accepted that the factor of safety should not be less than 1.5 for permanent work and not less than 1.25 for temporary work." It is not prescriptive on the design of anchors, but provides minimum safety factors recommended for design of individual anchors.

Another example is the code of practice on Surface Rock Support for Underground Mines (MOSHAB, 1999). This code is prescriptive in one aspect - "the requirement to install surface rock support in high headings (i.e. those greater than or equal to a nominal 3.5 metres in height) in all Western Australian underground mines unless a documented geotechnical risk assessment justifies otherwise. Where surface rock support is installed, it shall be applied to backs and side walls that are a nominal 3.5 metres from the floor of the excavation." This prescription removes completely the design decision from the rock engineer. The requirement for surface support, irrespective of the ground conditions, increases mining costs. However, although mining costs may be increased, improved safety may result in net value creation.

The benefits of design codes and codes of practice are that they remove any doubt as to the requirements and therefore will almost certainly benefit safety as indicated above. However, they must generally cater for the worst conditions and therefore will almost always be conservative, which is not usually advantageous in mining. Further, a design code must take account of the behaviours and conditions relevant to the rock mass and boundary conditions in which the excavation is made. This implies that these behaviours and conditions are well known and that the design methods are applicable. This may be the case in civil engineering in which common conditions are regularly encountered. However, behaviours and conditions in a mining environment may change rapidly, implying that design methods and designs must change correspondingly.

\section{Perceived disadvantages of design codes and a solution}

An example of a prescriptive design is contained within the former Guidelines for the Preparation of a Mandatory Code of Practice to combat rock fall and rockburst accidents in narrow tabular metalliferous mining in South Africa, which can be downloaded from the Department of Minerals and Energy website (DME, 2007). These guidelines represent generally good design practice (Stacey, 2004). However, it is pertinent to consider several design recommendations/specifications contained within the code guidelines.

In Clause 10.9.3 dealing with stope or panel support, "The strategy must describe a methodology to select the most appropriate support design requirements (e.g. energy absorption capability, yieldability, and areal coverage), to reduce the risk of rockfall and rockburst damage. The recommended design methodology for tabular hard rock mines is described in Appendix 1. However, where a different methodology is used, it must be scientifically shown to be equally effective to the methodology described in Appendix 1 of this document."

In Appendix 1, Clause 1.1 dealing with the stope face area, "The support resistance and energy absorption requirements must be determined in accordance with the methodology described in this Appendix. Where support resistance and energy absorption requirements are not determined, the values of $50 \mathrm{kN} / \mathrm{m}^{2}$ and $60 \mathrm{~kJ} / \mathrm{m}^{2}$ must be used respectively." 
In Clause 2.2 dealing with control of rockfalls, "In order to control rockfalls it is necessary to analyse the fallout thickness to determine the support resistance criteria that would prevent rockfalls. The cumulative percentage fallout thickness must be determined for a particular horizon and the support resistance of a particular stope support system must be capable of preventing at least $95 \%$ of all fallouts."

In Clause 2.3 dealing with reduction of rockburst damage, "A support system must be able to stabilise the stope hangingwall for $95 \%$ of the fallouts. The velocity of ejection is assumed to be $3 \mathrm{~m} / \mathrm{s}$ unless verified by measurements."

These prescriptive clauses remove the professional responsibility from the designer to choose (and justify) his own method and loadings. Although there is reference to risk assessments in the document, there is no requirement as far as risk is concerned, for example, to follow up on Clause 10.9.3 requirement referred to above. The specification that support must be able to stabilise $95 \%$ of the fallouts implies that it is being designed to allow failure in $5 \%$ of the cases. The fact that the specification is a load capacity criterion only means that little consideration is taken of small blocks that may fall between supports - a block with a volume of as little as $0.01 \mathrm{~m}^{3}$ could cause significant injury in a static environment; under seismic conditions, significant injury could result from failure of even smaller blocks. The specified load capacity design criterion also makes no consideration of other mechanisms of failure such as rotation, which could cause failure of supports at lower gravity loads. Further, the specifications do not take into account different mining conditions, different mining depths, different mining methods, etc. Thus, whilst the generic requirements of the code are commendable, the addition of the specific prescriptive requirements actually defeats the object. As long as the designer complies with the prescriptions, he cannot be held accountable for the failure of the design, nor does he need to revise the design as a result of a failure.

It is believed that prescriptive design codes are a substantial reason for the lack of design, development and implementation of new and more effective support methods. Design codes will tend to stifle innovative engineering - designers may just follow the 'rules' rather than thinking carefully about each situation and developing appropriate and new solutions in each case. Designs produced by code will usually be safe, but may often not be appropriate and in some cases may not be safe.

A further negative associated with a 'rule' is that of changing it once it has been established. It is often relatively easy to establish rules, which may have little basis and, with good intentions, be the first estimate. Changing such rules at a later stage may be much more difficult, particularly if a reduction of conservatism is involved.

It is considered that, instead of being prescriptive regarding design, an alternative approach would be to be prescriptive regarding the possibilities of provision of good quality data for input into design. This is the approach that has been adopted in Eurocode 7: Geotechnical Design (Eurocode, 1997) (the referenced code may not be the most recent version, but is satisfactory for the purposes of this paper).

Rather than specifying how the design must be carried out, the code specifies what must be done to provide data for design. This corresponds with Bieniawski's "Minimisation of Uncertainty" design principle (Bieniawski, 1992; Stacey, 2006).

According to Eurocode 7, geotechnical designs may be based on calculations, prescriptive measures, models and load tests, the observational method, or combinations of the approaches. Numerous relevant clauses from the code are quoted below.

The code states, "the assumptions, data, calculations and results of the verification of safety and serviceability shall be recorded in a Geotechnical Design Report. The level of detail of Geotechnical Design Reports will vary greatly, depending on the type of design. For simple designs, a single sheet may be sufficient. The report should normally include the following items, with cross-referencing to the Ground Investigation Report and to other documents which contain more detail:

- A description of the site and surroundings.

- A description of the ground conditions.

- A description of the proposed construction, including actions.

- Design values of soil and rock properties, including justification, as appropriate. 
- Statements on the codes and standards applied.

- Statements of the level of acceptable risks.

- Geotechnical design calculations and drawings.

- A note of items to be checked during construction or requiring maintenance or monitoring.

The Geotechnical Design Report shall include a plan of supervision and monitoring, as appropriate. Items which require checking during construction or which require maintenance after construction shall be clearly identified in the report. When the required checks have been carried out during construction, they shall be recorded in an addendum to the report.

The suitability of the construction procedures and the sequence of operations shall be reviewed against the ground conditions which are encountered and the predicted behaviour of the structure shall be compared with the observed performance. The design shall be assessed on the basis of the results of the inspection and control. If necessary, the structure shall be redesigned.

It shall be checked that the principles used in design are appropriate for the geotechnical features of the ground which are encountered."

Supervision of construction is, amongst other things, for the purpose of "checking the validity of the design assumptions; identifying the differences between the actual ground conditions and those assumed in design; checking that the construction is carried out according to the design."

In the recent Crandall Canyon Mine disaster (United States Senate, 2008) it is indicated that the "failure of the review process highlights the urgent need for reform and strengthening of the review process for mining plans ..." In this document it is stated that this reform should codify the required steps in the roof control process more explicitly.

The requirements for geotechnical investigations in Eurocode 7 are substantial and too detailed to be included in full in this paper. They include preliminary investigations (effectively the desk study and field reconnaissance involved in early site investigation) and design investigations "to provide the information required for an adequate and economic design of the permanent and temporary works; to provide the information required to plan the method of construction; to identify any difficulties that may arise during construction." The results are compiled into a ground investigation report consisting of "the following two parts:

- Presentation of available geotechnical information including geological features and relevant data.

- Geotechnical evaluation of the information, stating the assumptions made in the derivation of the geotechnical parameters."

It should be noted that many of these items correspond well with the design process (Bieniawski, 1992), and with the requirement for definition of the acceptable risks, which is dealt with further in Section 5 below. The importance of monitoring and review to ensure that design objectives are being satisfied and that the design is valid, as a part of the design process (Stacey, 2006), is emphasised.

Many mining companies are notoriously weak when it comes to investigation, testing, inspection and documentation of these data in a retrievable database. Often such systems rely on an individual, and the information is lost when that individual moves from the mine. A good and secure system of databasing and communicating information is invaluable to design and operation and is essential for good engineering practice. An example of such a system, and the benefits that have accrued, are described briefly by Little et al. (2007).

Eurocode 7 is aimed at the civil engineering field, but there is no reason why its requirements should not apply equally to rock engineering in mining. It represents good engineering design practice, which should be practised in mining as a matter of course. It is considered that such a code should be applicable for geotechnical engineering in the mining industry. 


\section{$4 \quad$ Is such regulation appropriate in the mining industry?}

In the mining industry, the requirement for rules to guide the reporting of mineral reserves and resources is internationally accepted. The following is a quote from the Australasian JORC Code (2004):

"The main principles governing the operation and application of the JORC Code are transparency, materiality and competence.

- Transparency requires that the reader of a Public Report is provided with sufficient information, the presentation of which is clear and unambiguous, to understand the report and is not misled.

- Materiality requires that a Public Report contains all the relevant information which investors and their professional advisers would reasonably require, and reasonably expect to find in the report, for the purpose of making a reasoned and balanced judgement regarding the Exploration Results, Mineral Resources or Ore Reserves being reported.

- Competence requires that the Public Report be based on work that is the responsibility of suitably qualified and experienced persons who are subject to an enforceable professional code of ethics."

This paper deals with design codes. If the word 'Public' was replaced with 'Design' in the above JORC Code principles, it is considered that the statements would not be out of place regarding the protection of the investors' interests. Have failures due to inadequate design not resulted in large losses to investors? Such cases are more commonly documented for the civil engineering industry, since the consequences usually involve the public. As pointed out by Steffen (1997), geotechnical risks are just as great, if not greater than, geological risks. Investors should, therefore, be equally concerned about the veracity and validity of geotechnical information that is the basis of geotechnical design in mining. Steffen (1997) suggested that reporting on geotechnical issues should be governed by codes, as for minerals reporting. At present in the mining industry, geotechnical information, which is the basis for design, is usually very sparse, often of a generalised and non-specific nature, and sometimes non-existent. A geotechnical code corresponding with the mineral resources definition codes would remedy this situation.

\section{The way to go}

Greater engineering rigour must be introduced into the mining rock engineering field. There is currently too little engineering in rock engineering (Pells, 2008). Risk must be an integral aspect of the design and the level of acceptable risk, which must form the basis of the design, must be defined at the outset by the mining executives, who are empowered and responsible for making such risk decisions. In this regard it is appropriate to record some of the general precepts concerning safety and reliability identified by Wong (2005):

- "Nothing can be $100 \%$ reliable and safe" and "human beings, one day, will invariably make a mistake." Mining companies often claim a "zero tolerance" approach to accidents. As indicated by this precept, this is not achievable, and can only be a goal.

- "Reliability cannot be predicted without statistical data; when no data are available the odds are unknown." Reliability can only be predicted if statistical data exist. It is commonly the case in mining that there are few or no data on which to base designs or evaluations of stability, particularly in the geotechnical environment. This highlights the need for improved geotechnical data collection and data management techniques in the mining industry.

- "Making things safe and reliable costs money. Engineers will always need to cost the price of failure for comparison." In mining, optimism prevails and there is little expectation that a disaster will occur. When it does, it usually comes as a 'surprise'. Consequently, the cost of such a disaster is rarely balanced against the cost of ensuring safety and stability. If it were, it is likely that in almost every case it could be demonstrated that improved engineering would generate value to the mining operation even if it did involve additional cost. The common obsession with cost control, usually by cost cutting, is likely to destroy value in most cases. 
Ethics in engineering design are directly associated with safety (Schinzinger and Martin, 2000), and safety is directly associated with risk. It is considered relevant here to quote three of the responsibilities of registered persons in terms of the Code of Conduct of the Engineering Council of South Africa (ECSA, 2006). "Registered persons:

- Must discharge their duties to their employers, clients, associates and the public effectively with skill, efficiency, professionalism, knowledge, competence, due care and diligence.

- Must at all times have due regard and priority to public health, safety and interest.

- Must when providing professional advice to a client or employer, and if such advice is not accepted, inform such client or employer of any consequences which may be detrimental to the public health, safety or interests and at the same time inform the Council of their action."

Schinzinger and Martin (2000) give the following definition of safety: "A thing is safe if, were its risks fully known, those risks would be judged acceptable by a reasonable person in light of settled value principles." Regarding acceptability of risk, they quote the description due to Rowe (1979): "A risk is acceptable when those affected are generally no longer (or not) apprehensive about it." Wong (2005) states, "It is generally accepted that risks which have a fatal injury (hazard) rate of $10 \times 10^{-5}$ or more are unacceptable." The acceptability of risk is also dependent on whether the exposure to the risk is voluntary or involuntary. According to Schinzinger and Martin (2000) individuals are more ready to accept voluntary risks, even if these are a thousand times more likely to result in a fatality than the involuntary risks. The question of acceptable risk has also been dealt with by Terbrugge et al. (2006) and Steffen and Terbrugge (2004), who have suggested the use of internationally accepted design criteria. They proposed the use of an annual probability of loss of life of $10^{-4}$. Another approach could be to adopt the policy that employees should be as safe at work as they are at home. The latter risk is quantified in some developed countries. In the mining environment, management can and should take the decisions regarding level of risk that is acceptable in terms of its company policy. It is suggested that the acceptable risk, based on corporate risk policy, should be defined in the first step of the design process, which then logically would be the basis of the design (Stacey et al., 2007).

It is considered entirely appropriate for geotechnical design in mining to be subjected to the same level of rigour as is required for geological definition in terms of the various mineral codes (for example, JORC Code, 2004). This should not be in the form of prescriptive design, but rather in the form of prescriptive requirements relevant to the input to, and validation of, the geotechnical design. Many of the requirements of Eurocode 7 are directly relevant to this goal. The benefit of such a geotechnical engineering design code would be improved engineering, enhanced safety and almost certainly greater value generated for the mining company.

\section{Conclusions}

It is time that the guesswork that commonly forms the basis of geotechnical engineering design in mining was replaced with a much more rigorous engineering design approach. This will be achieved if the collection of design input data and the generic requirements of the design were to be prescribed by a code. It has been shown in this paper that the mining industry could benefit greatly from the implementation of a code such as Eurocode 7. It is interesting to note that this code requires statements as to the levels of acceptable risk, which has been proposed as an input design objective in mining as discussed above. A geotechnical design code equivalent to the codes for mineral resource definition could provide great benefit to mining companies and investors and could lead to much better performance of mining projects.

\section{References}

Bieniawski, Z.T. (1992) Invited Paper: Principles of engineering design for rock mechanics, Rock Mechanics, Proceedings 33rd U.S. Symposium on Rock Mechanics, Tillerson and Wawersik (editors), Balkema, pp. 1031-1040.

DME (2007) Guideline for the compilation of a mandatory Code of Practice to combat rock fall and rockburst accidents in tabular metalliferous mines, DME 16/3/2/1-A3, last revision date 1 February 2002, www.dme.gov.za. 
ECSA (2006) Rules of Conduct for Registered Persons: Engineering Profession Act, 2000 (Act No. 46 of 2000), Board Notice 15 of 2006, http://www.ecsa.co.za.

EUROCODE 7 (1997) National Application Document, for use in the UK with ENV 1997-1:1994.

JORC Code (2004) Australasian Code for Reporting of Exploration Results, Mineral Resources and Ore Reserves, Prepared by The Joint Ore Reserves Committee of The Australasian Institute of Mining and Metallurgy, Australian Institute of Geoscientists and Minerals Council of Australia (JORC), Effective December 2004.

Little, M.J., Bye, A.R. and Stacey, T.R. (2007) Safety and financial value created by good slope management strategies and tactics, Proceedings 6th Large Open Pit Mining Conference, Perth, Aus.I.M.M., pp. 77-85.

Minerals Act and Regulations (2001) South African Minerals Act and Regulations, Lex Patria, Durban.

MOSHAB (1999) Surface Rock Support for Underground Mines, Code of Practice, Mines Occupational Safety and Health Advisory Board, Western Australia, 16 p.

Pells, P.J.N. (2008) What happened to the "mechanics" in rock mechanics and the "geology" in engineering geology? Proceedings 6th International Symposium on Ground Support in Mining and Civil Engineering Construction, Southern African Institute of Mining and Metallurgy, Cape Town, 31 March-2 April, pp. 1-36.

Rowe, W.D. (1979) What is an acceptable risk and how can it be determined? In Energy Risk Management, G.T. Goodman and W.D. Rowe (editors), Academic, New York.

SAICE (1989) Lateral Support in Surface Excavations, South African Institution of Civil Engineers, Geotechnical Division, $218 \mathrm{p}$.

Schinzinger, R. and Martin, M.W. (2000) Introduction to Engineering Ethics, McGraw-Hill.

Stacey, T.R. (2004) The link between the design process in rock engineering and the code of practice to combat rock fall and rockburst accidents, Journal Of the Southern African Institute of Mining and Metallurgy, Vol. 104, No. 1, pp. 29-33.

Stacey, T.R. (2006) Design - a Strategic Issue, Proceedings 2nd Int. Seminar on Strategic vs Tactical Approaches in Mining, Perth, Australian Centre for Geomechanics, Section 4, 13 p.

Stacey, T.R., Terbrugge, P.J. and Wesseloo, J. (2007) Risk as a rock engineering design criterion, in Challenges in Deep Level Mining, Potvin, Hadjigeorgiou and Stacey (editors), Australian Centre for Geomechanics, pp. 17-23.

Steffen, O.K.H. (1997) Planning of open pit mines on a risk basis, Journal of the Southern African Institute of Mining and Metallurgy, Vol. 97, March/April, pp. 47-56.

Steffen, O.K.H. and Terbrugge, P.J. (2004) Designing open pit slopes with risk, Proceedings Colloquium The Management of Risk in the Minerals Industry, Southern African Institute of Mining and Metallurgy, $10 \mathrm{p}$.

Terbrugge, P.J., Wesseloo, J., Venter, J. and Steffen, O.K.H. (2006) A risk consequence approach to open pit slope design, Journal of the Southern African Institute of Mining and Metallurgy, Vol. 106, No. 7, pp. 503-511.

United States Senate (2008) Report on the August 6, 2007 Disaster at Crandall Canyon Mine, United States Senate, Health, Education, Labor and Pensions Committee, Edward M. Kennedy, Chairman, March 6, 2008.

Wong, W. (2005) How did that happen? - Engineering Safety and Reliability, Professional Engineering Publishing Limited, London and Bury St Edmonds, UK. 